\title{
A Rule Induction Framework on the Effect of 'Negative' Attributes to Academic Performance
}

\author{
https://doi.org/10.3991/ijet.v16i15.24269
}

Ivan Henderson V. Gue $\left.{ }^{1}{ }^{\bowtie}\right)$, Alexis Mervin T. Sy², Ailene B. Nuñez ${ }^{2}$, Pocholo James M. Loresco ${ }^{2}$, Jaychris Georgette Y. Onia ${ }^{2}$, Manuel C. Belino ${ }^{2}$, Jaychris Georgette Y. Onia ${ }^{3}$

${ }^{1}$ De La Salle University, Manila, Philippines

${ }^{2}$ FEU-Institute of Technology, Manila, Philippines

${ }^{3}$ Silliman University, Dumaguete, Philippines

ivan.gue@dlsu.edu.ph

\begin{abstract}
Attaining high retention rates among engineering institutions is a predominant issue. A significant portion of engineering students face challenges of retention. Academic advising was implemented to resolve the issue. Decision support systems were developed to support the endeavor. Machine learning have been integrated among such systems in predicting student performance accurately. Most works, however, rely on a black box model approach. Rule induction generates simpler if-then rules, exhibiting clearer understanding. As most research works considered attributes for positive academic performance, there is the need to consider 'negative' attributes. 'Negative' attributes are critical indicators to possibility of failure. This work applied rule induction techniques for course grade prediction using 'negative' attributes. The dataset is the academic performance of 48 mechanical engineering students taking a machine design course. Students' attributes on workload, course repetition, and incurred absences are the predictors. This work implemented two rule induction techniques, rough set theory (RST) and adaptive neuro fuzzy inference system (FIS). Both models attained a classification accuracy of $70.83 \%$ with better performance for course grades of 'Pass' and 'High'. RST generated 16 crisp rules while ANFIS generated 27 fuzzy rules, yielding significant insights. Results of this study can be used for comparative analysis of student traits between institutions. The illustrated framework can be used in formulating linguistic rules of other institutions.
\end{abstract}

Keywords — machine learning, academic advising, mechanical engineering

\section{$1 \quad$ Introduction}

Student retention is an indicator of an educational institution's performance. However, many engineering educational institutions experience problems of low student retention. Ref. [1] declares one of three engineering students graduates on time while one of two graduates at a longer duration. Academic support systems were implemented to address this problem. Among them, academic advising is widely implemented. The 
support system engages holistic learning between professors and students [2]. This aspect positions academic advising as an endeavor critical to the student's academic journey [3]. The support system helps students improve their academic prowess, understand their degree, and develop their knowledge in life's aspects. These benefits are derived from the insightful suggestions that students obtain from their advisers. The endeavor enables goals setting, professional inquiries, and academic counseling [4].

According to [5], several approaches and theories can be used for academic advising. Ref. [5] discussed the method of approaching can be prescriptive, developmental, or intrusive. The method can also be according to the discipline that the mentor wants to improve. It can be learning-centered, strength-based, appreciative inquiry, or social constructivism.

Among the previously mentioned, prescriptive and developmental approaches are among the widely recognized [6]. Ref. [7] describes prescriptive advising as analogous to a doctor-patient relationship. The relationship is the student have an 'illness', or academic problem, which is treated by the professor with a 'diagnosis', or academic advising. On the other hand, the developmental approach requires a professor to have developmental goals in mind. Whichever is better between the two is a debatable subject among the academe [8]. Ref. [9] did a work on students from South Carolina and proved students are more satisfied from the developmental approach. Findings of [10] state that prescriptive advising yields better results. Ref. [11] highlights the impact of this approach to on-time graduations. These approaches are constrained if the students fail to recognize their personal academic problem. This constraint needs intrusive advising to have a central role. Intrusive advising is a direct approach to decreasing student attrition and late graduations. It is focused on identifying 'at-risk' students and taking action before encountering any serious academic problem [12]. Findings of [13] presents retention rates of $98 \%$ within a university upon implementation of intrusive advising.

Effective academic advising is attainable with proper identification of 'at-risk' students. Decision support systems (DSS) streamlines the process. The framework proves to be an indispensable tool as early warning system. This early detection significantly improves academic advising. Early works on DSS trace back to ref. [14] in 1995, based on the Scopus database. The system automated and optimized course listing for business students. Ref. [15] is a DSS that provides real-time information on the academic progress of engineering students.

Recently, machine learning (ML) tools are gaining prominence among research works. ML tools have several applications and have even significant contributions to other fields such as sustainable development [16]. The emergence of these tools has further advanced the DSS' capabilities. The work of [17] sought to predict the performance of five generations of sophomore engineering students using artificial neural network (ANN). Ref. [18] also employed ANN. They presented a prediction model for failure-prone students in a blended learning course.

Difficulties in ML techniques, however, is the black box model approach. Complexities in reasoning are a barrier towards understanding relationships between variables. Not knowing the model's internal reasoning result to overdependence to the predictions. Ref. [19] argued that interpretability is important to in realizing whether a 
model's approximation is reasonably sound. Rule induction algorithms overcome this barrier through formulation of simple if-then rules [20]. Algorithms such as adaptive neuro-fuzzy inference system (ANFIS) and rough set theory (RST) were identified in literature as promising for rule induction. Ref. [21] argued that ANFIS has potential for rule induction as fuzzy logic systems are notably interpretable. Meanwhile, [22] argued that RST can generate simple if-then rules with high interpretability and can also utilize asymmetric and incomplete dataset.

ANFIS was used in the work of [23]. They developed a student classification tool in predicting student performance highlighting the student's interest, talent, and motivation as key attributes. RST proved to have relatively high accuracy in predicting student performance. Ref. [24] showcased an accuracy rate of $90.50 \%$ in predicting performances of students in programming. Ref. [25] achieved an accuracy of $98.30 \%$ in predicting final course grades based on class performance.

Attributes used in previous works has served as benchmarks in the development of DSS. Notably, attributes affecting positive or higher academic performance was considered. Improving retention rate, however, require understanding attributes resulting to failures. Ref. [26] noted that resolving the dropout rate requires analyzing the underlying factors affecting poor performance. As evident in literature, existing works assessed the causal factors of academic failure. Ref. [27] found that stress overload impacts failure rate for freshmen students. Meanwhile, [28] identified 'negative' academic attributes as having significant effect to poor performance. They determined such attributes can originate from socio-demographic, academic, psychological, and health factors.

As 'negative' attributes are required in identifying 'at-risk' students, understanding its relationship to academic performance is necessary. ML techniques can recognize patterns in the relationship and provide a highly accurate model approximation. However, black box model approaches inhibit verifying the model's internal reasoning. The lack of verification is a barrier for academic adviser's utilization. Rule induction techniques circumvents the problem through formulation of linguistic rules, enabling ease of insight generation. Therefore, this work focuses on rule induction techniques of engineering student performance using 'negative' attributes as predictors. The considered 'negative' attributes in this work were workload, course repetition, and absences. Selection process of the attributes are further elaborated in Section 3. This work is an extension of our previous work, [29]. As our previous work focused on rule induction using RST, this work considers ANFIS as a rule induction technique as well. The advantage of ANFIS is its ability to generate fuzzy rules providing considerations for uncertainty.

We also present here the DSS framework for implementing the rule induction techniques. The framework aims to predict academic performance of at-risk students. The framework can either be used as an offline tool or as a software-based tool, such as [30].

The following discussion of this paper are as follows. Section 2 details the DSS framework and the theoretical background of the rule induction techniques. Section 3 discusses the characteristics of the data used and the attributes' categorization. Section 4 provides the details of the two techniques' performance, formulated rules, and tuned membership function of ANFIS. Section 5 discusses the insights obtained from the formulated rules and its implications. Lastly, section 6 summarizes this work and enumerates the suggested future works. 


\section{$2 \quad$ Application Design}

\subsection{Decision Support System Framework}

The proposed DSS framework is updated on a per academic term basis. Figure 1 depicts this framework. The framework is designed to integrate the institution's academic records, illustrated as the historical database. These records contain students' metric on academic performance, such as attendance, course grades, year level, and units enrolled. Relevant metrics from the records are retrieved and are used by the framework. Patterns in the database are then recognized through rule induction techniques. Rule induction techniques yield rules between academic attributes and academic performance. The rules are provided to the academic adviser to generate insights on student characteristics. Mixed with personal perspective, the additional insights help the adviser formulate robust advice. After each term, the students' performance is tallied in the academic records.

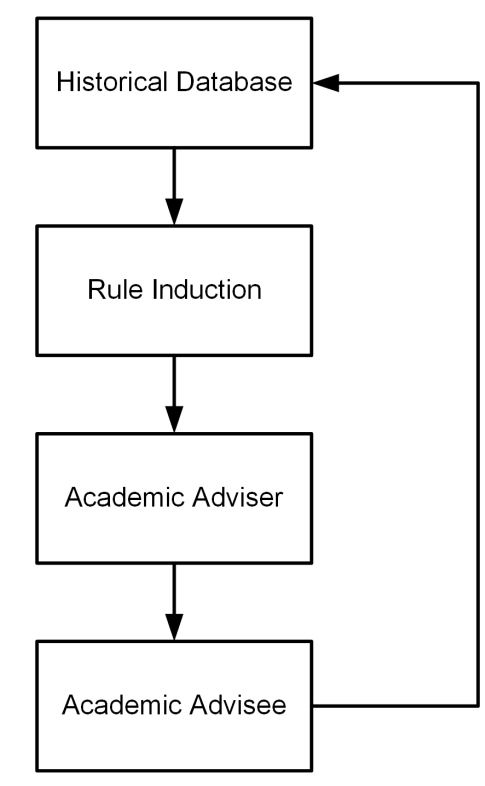

Fig. 1. DSS framework with rule induction techniques

\subsection{Adaptive Neuro Fuzzy Inference System}

ANFIS is a rule induction technique integrating core concepts of ANN and fuzzy logic [31]. Developed by [32], the technique utilizes five nodal layers in its architecture. The architecture is depicted in Figure 2 where data flows from input to output. The five layer comprises of fuzzification, rule firing, normalization, defuzzification, and summation. 


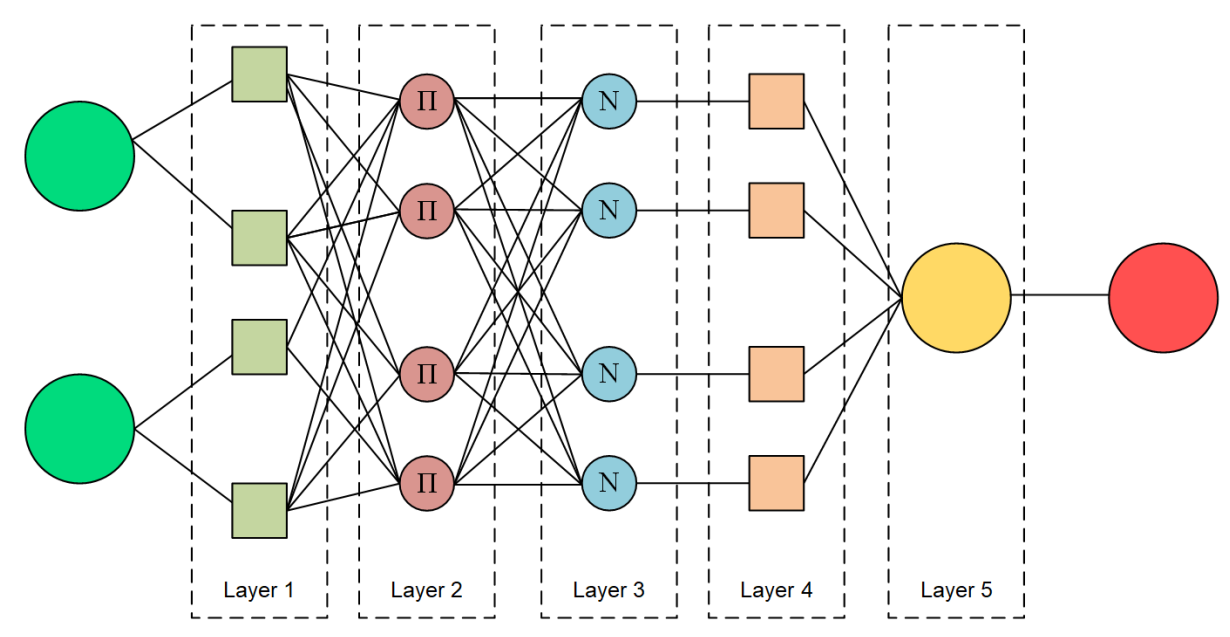

Fig. 2. Visual representation of ANFIS architecture

For simplicity, the discussion focuses on a two input, $x$ and $y$, and one output, $z$, scenario. Input $x$ has possible attributes of $A_{i}$ while input $y$ has possible attributes of $B_{i}$. The work of [33] provides a general overview of the architecture's algorithmic process. The first layer function is fuzzification of the inputs. The function is represented by eq. (1) where $O_{i}{ }^{l}$ indicates the output of $i$ th node in the first layer. Calculation of the layer's output is based on the membership function, $\mu(x)$, depicted in eq. (2). The variables $a, b$, and $c$ are termed as the premise parameters and determine the membership function's form.

$$
\begin{gathered}
O_{i}^{1}=\mu_{A_{i}}(x) \\
\mu_{A_{i}}(x)=\frac{1}{1+\left|\frac{x-c}{a}\right|^{2 b}}
\end{gathered}
$$

The output of the second layer, $\mathrm{O}_{i}{ }^{2}$, is depicted in eq. (3). The layer's function is in firing the proper rules of the ANFIS architecture. The rules are generated during the tuning procedure. Outputs $O_{i}{ }^{2}$ are then normalized through the third layer. The normalization process is done using eq. (4).

$$
\begin{gathered}
O_{i}^{2}=w_{i}=\mu_{A_{i}}(x) \times \mu_{B_{i}}(y) \\
O_{i}^{3}=\bar{w}_{i}=\frac{w_{i}}{\sum_{i} w_{i}}
\end{gathered}
$$

Normalized outputs form the third layer, $O_{i}{ }^{3}$, are defuzzied in the fourth layer. The computed output, $\mathrm{O}_{i}{ }^{4}$, is obtained from eq. (5) where $f_{i}$ are the yields of ANFIS' if-then rules such that if $x$ is $A_{i}$ and $y$ is $B_{i}$ then $f_{i}$. The variable $p, q$, and $r$ are termed as the consequent parameters. The final output, $z$, is the fifth layer's output, $O_{i}{ }^{5}$ and is calculated through summation of $\mathrm{O}_{i}{ }^{4}$, as represented by eq. (6).

$$
O_{i}^{4}=\bar{w}_{i} f_{i}=\bar{w}_{i}\left(p_{i} x+q_{i} y+r_{i}\right)
$$




$$
O_{i}^{5}=\sum_{i} \bar{w}_{i} f_{i}
$$

\subsection{Rough Set Theory}

RST is a rule induction technique integrating approximations on the boundaries of ordinary sets [34]. The approximations provide better classification accuracy with the laxing of boundaries, as illustrated in Figure 3. Ref. [35] provides a detailed discussion on the algorithmic process of RST. The technique follows an information system space $I S$ which contains the inputs and the attributes. The input set is denoted as set $U$ while the attribute set is denoted as $A$. Set $U$ consists of the input variables $x_{i}$ while set $A$ contains the attributes $a_{i}$. The output set, on the other hand, is denoted as set $D$, containing the output variables $d_{i}$.

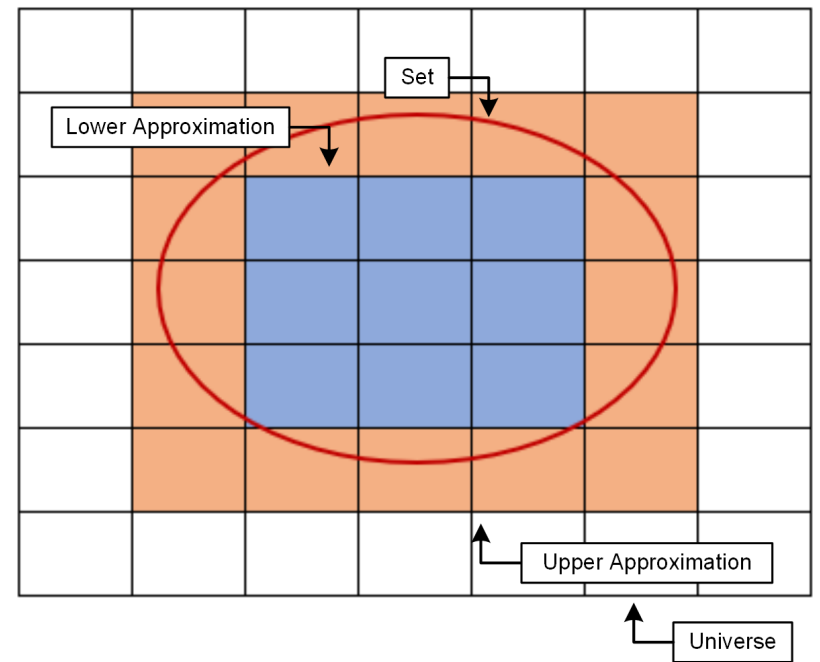

Fig. 3. Visual representation of RST

Elements of set $U$ are used in formulating the discernibility matrix $D M$. Elements of this matrix, $d m_{i j}$, pertains to sets containing the discernible attributes between input variables. For example, if $x_{l}$ has attributes of $\left\{a_{1}=1, a_{2}=2\right\}$ and $x_{2}$ has $\left\{a_{1}=3, a_{2}=2\right\}$, then $d m_{12}$ is $\left\{a_{2}\right\}$. The discernibility function $f(A)$ is then used for each element of $D M$. The function follows a disjunction operator $(V)$ when dealing with attribute of the same set and conjunction operator $(\Lambda)$ for different set. For example, if $d m_{12}$ is $\left\{a_{2}\right\}$ and $d m_{23}$ is $\left\{a_{1}, a_{3}\right\}$ the resulting discernibility function is $a_{2} \wedge\left(a_{1} \vee a_{3}\right)$ or $a_{2} a_{1} \vee a_{2} a_{3}$. The resulting form of $f(A)$ is the identified reducts of RST. The reducts are sets that have minimum number of attributes describing the dataset. The core, on the other hand, are attributes that are integral in describing the dataset. A reduced set $A$ is obtained from the reducts. Of which, a different $D M$ is formulated. The relative discernibility function $f_{i}(A)$ is used in identifying the relative reducts. The relative reducts are then formed 
together in generating the rule table. The table describes the crisp rules pertaining to the dataset's recognized patterns.

\section{Case Study}

The historical dataset was extracted from the academic database of the institution, FEU-Institute of Technology. Characteristics of 48 mechanical engineering students were used as attributes for the rule induction techniques. Course grades from their machine design course was assigned as the decision variable. The machine design course is an engineering course engaging students in the analysis of mechanical properties and analysis of mechanical stress. The course is ideally taken among third year mechanical engineering students. Tasks and exams of the course requires extensive computational and analytical skillsets.

The identified 'negative' academic attributes in the case study are workload, course repetition, and incurred absences. Selection of the three attributes was based on insights of previous works and its availability in the academic records. Table 1 enumerates the attributes and decision of this work. The decision variable or the output was categorized according to the institution's grading scheme with 1.0 as the passing grade and 4.0 as the perfect grade.

The first attribute considered is the student's workload. Workload reflects the weight of assigned tasks to the student. This attribute affects the mental stress experienced by engineering students [36]. Stressed caused by significant workload result to poor academic performance. As [37] highlighted, workload is positively correlated with test anxiety, potentially resulting to poor test results. Ref. [38] also noted that increased workload can lower student motivation. There were cases, however, where the contrary is true. Ref. [39] found the attribute act as the initial step towards efficient learning, arguing its relevance in longitudinal research. Meanwhile, [40] argued that workload affect positive academic performance with the support of student interest and teaching quality. As workload has significant implications to academic performance, the case study considered it for rule induction. In the case study, workload is reflected as the number of units enrolled. The units enrolled is a composite indicator of time spent in class, weight of assignments, and course difficulty. The metric provides a general approximation of student workload. The range of the category levels were based on the existing workload category of the institution.

The second attribute is the student's course repetition. Course repetition is indicated as the number of times the student enrolled in the subject. Ref. [41] argued that the attribute can result to demotivation, leading to poor academic performance. Ref. [42] noted that students who retook classes is likely to drop out. Meanwhile, [43] found that students who repeated a course in economics attained lower course grades relative to their peers. However, some works found positive effect of course repetition. Findings of [42] revealed higher scores for retakers relative to the first timers. The findings suggest that with proper motivation, retakers have a good chance of attaining a significantly better grade. Ref. [44] also supplemented this finding as students who took a finance class for the second time attained higher course grade. Overall, course repetition may 
reduce student motivation or improve learning ability which is dependent on the student's inherent traits. As course repetition can result to reduced motivation and increased chance of dropping out, this work considers the attribute. In the case study, the range for this attribute's category level was based on perceived common course repetition among students.

The third attribute is the student's incurred absences. Incurred absences are instances when the student did not attend the class. In literature, the attribute has a notable influence on poor course grade. Ref. [45] found high correlation for low attendance rate and low course grade. They suggested compulsory attendance for higher academic rating. Ref. [46] has similar finding for civil engineering students in Ireland. Ref. [47] discovered that even among graduate students, high incurred absences correlate with lower course grades. Lastly, Ref. [48] found the impact of absences to lower grades in a calculus class. Predominantly, incurred absences have negative impact to course grades. This work, therefore, considered the attribute in the case study. The range for the category levels of this attribute were based on the maximum allowable instances of the institution.

The software, ROSETTA, generated the crisp rules using RST while MATLAB generated the fuzzy rules using ANFIS. A 70:30 approach was used for the model's training and testing phase.

Table 1. Attributes and Decision Criteria of Dataset

\begin{tabular}{|l|c|c|}
\hline Attribute/Decision & Category Level & Numerical Range \\
\hline \multirow{4}{*}{ Workload } & $1-$ Underload & $<16$ units \\
\cline { 2 - 3 } & $2-$ Normal Load & 16 to 20 units \\
\cline { 2 - 3 } Course Repetition & $3-$ Overload & $>20$ units \\
\cline { 2 - 3 } & $1-$ None & $<1$ instance \\
\cline { 2 - 3 } Incurred Absences & $2-$ Low & 1 to 2 instances \\
\cline { 2 - 3 } & $3-$ High & $>2$ instances \\
\cline { 2 - 3 } & $1-$ Low & $<2$ instances \\
\hline \multirow{3}{*}{ Course Grade } & $2-$ Normal & $>4$ instances \\
\cline { 2 - 3 } & $3-$ High & $<1.0$ \\
\cline { 2 - 3 } & $1-$ Fail & $>3.0$ \\
\cline { 2 - 3 } & $2-$ Pass & to 3.0 \\
\hline
\end{tabular}

\section{Results}

Figure 4 shows the categorical level's membership functions in the first layer of ANFIS. The y-axis depicts the degree of truth and the x-axis depicts the attribute's value. Parameters, $a, b$, and, $c$, of the membership functions were tuned through the training phase. Tuning of the three parameters resulted to ranges similar to the predefined categorical levels enumerated in Table 1. The ranges, therefore, coincide with the guidelines enumerated in Section 3. Meanwhile, Figure 5 shows membership functions of the decision variable. These membership functions are found in the fourth layer 
of ANFIS. The membership functions are constants as represented by the figure. As the categorical levels are integers, the values are rounded off. The rounding off is depicted in the figure as ranges for ' 1 - Fail', '2 - Pass', and '3 - High'.

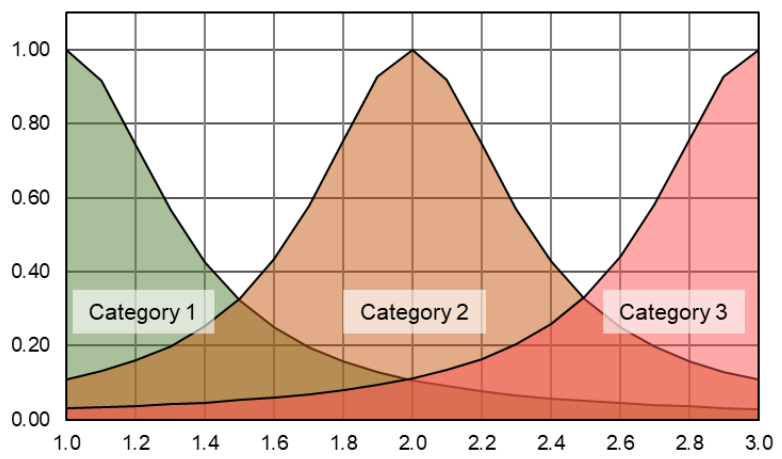

Fig. 4. Input membership functions of the three attributes

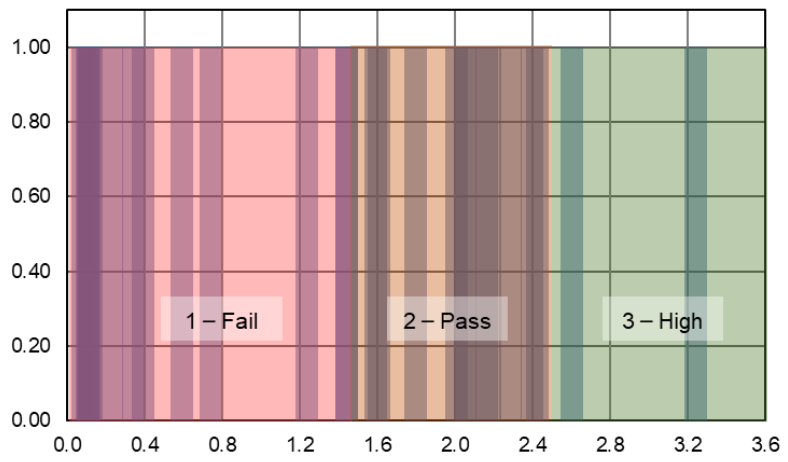

Fig. 5. Output membership functions of the decision variables

Figure 6 shows the confusion matrices obtained from both rule induction techniques. As shown in the figure, both models yielded similar classification accuracies of $70.83 \%$. Predicting 'Pass' and 'High' have higher accuracies as compared to predicting 'Fail'. The models, therefore, are more reliable in determining passing students than failing ones.

\begin{tabular}{|c|c|c|c|c|}
\hline \multicolumn{5}{|c|}{ RST } \\
\hline & \multicolumn{4}{|c|}{ Actual } \\
\hline \multirow{4}{*}{ 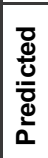 } & & 1 & 2 & 3 \\
\hline & 1 & 7 & 4 & 1 \\
\hline & 2 & 4 & 26 & 4 \\
\hline & 3 & 0 & 0 & 1 \\
\hline
\end{tabular}

\begin{tabular}{|c|c|c|c|c|}
\hline \multicolumn{5}{|c|}{ ANFIS } \\
\hline & \multicolumn{4}{|c|}{ Actual } \\
\hline \multirow{4}{*}{ 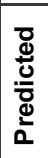 } & & 1 & 2 & 3 \\
\hline & 1 & 7 & 4 & 0 \\
\hline & 2 & 5 & 26 & 5 \\
\hline & 3 & 0 & 0 & 1 \\
\hline
\end{tabular}

Fig. 6. Confusion matrices of rule induction techniques 
The RST model formulated 16 crisp rules, as tabulated in Table 2. The table shows the possible course grades according to each attributes' category levels. Each rule has the possibility of yielding one or more outputs brought by the methodological structure of RST. Isolating to a single output, however, is necessary. The output with the highest accuracy rating during the training phase is assigned as the prediction output. A limitation in this model's rules is in the scope of the training data. Rules for combinations not evident in the training data were not formulated. The limitation was observed in the case of a data point with workload of ' 3 - Overload', course repletion of ' 1 - None', and incurred absences of ' 2 - Normal'.

Table 2. Crisp rules of the RST model

\begin{tabular}{|l|c|c|c|c|c|}
\hline \multirow{2}{*}{$\begin{array}{c}\text { Rule } \\
\text { No. }\end{array}$} & \multirow{2}{*}{ Workload } & \multirow{2}{*}{$\begin{array}{c}\text { Course } \\
\text { Repetition }\end{array}$} & \multirow{2}{*}{ Absences } & \multicolumn{2}{|c|}{ Course Grade } \\
\cline { 5 - 6 } & 1 & 1 & 1 & Possibilities & Prediction (Accuracy) \\
\hline 1 & 1 & 1 & 3 & 1 & $1(50.0 \%)$ \\
\hline 2 & 1 & 2 & 1 & 1 or 2 or 3 & $1(100.0 \%)$ \\
\hline 3 & 1 & 2 & 2 & 2 & $2(75.0 \%)$ \\
\hline 4 & 2 & 1 & 1 & 2 or 3 & $2(100.0 \%)$ \\
\hline 5 & 2 & 1 & 2 & 1 or 2 & $2(66.7 \%)$ \\
\hline 6 & 2 & 1 & 3 & 1 & $1(100.0 \%)$ \\
\hline 7 & 2 & 2 & 1 & 2 & $2(100.0 \%)$ \\
\hline 8 & 2 & 2 & 3 & 2 & $2(100.0 \%)$ \\
\hline 9 & 2 & 3 & 3 & 2 & $2(100.0 \%)$ \\
\hline 10 & 3 & 1 & 1 & 2 & $2(100.0 \%)$ \\
\hline 11 & 3 & 1 & 3 & 1 & $1(100.0 \%)$ \\
\hline 12 & 3 & 2 & 1 & 2 & $2(100.0 \%)$ \\
\hline 13 & 3 & 2 & 2 & 2 or 3 & $2(50.0 \%)$ \\
\hline 14 & 3 & 2 & 3 & 3 & $3(100.0 \%)$ \\
\hline 15 & 3 & 3 & 2 & $2(100.0 \%)$ \\
\hline 16 & & & & & \\
\hline
\end{tabular}

The ANFIS model formulated 27 fuzzy rules as tabulated in Table 3. Unlike the crisp rules, the fuzzy rules are not directly translatable needing the process of defuzzification. The fuzzy rules, however, derive insights on course grade prediction. Numerical outputs are tabulated in Table 3 and rounded off, similar to the illustration of Figure 5. The rounded off values, when compared with the predictions of Table 2, show similar results with the exclusion of ANFIS' rule no. 1. The rule yields a course grade of ' 2 Pass' while RST's rule no.1 yields ' 1 - Fail'. Difference between the rules is the result of the RST having three possible course grades. An advantage of the ANFIS model is its ability to produce output even for combinations not evident in the training data. This is evident in the case with workload of ' 3 - Overload', course repletion of ' 1 - None', and incurred absences of ' 2 - Normal'. The ANFIS' rule no. 20 provides a fuzzy rule for such combination. 
Table 3. Fuzzy rules of the ANFIS model

\begin{tabular}{|c|c|c|c|c|c|}
\hline \multirow{2}{*}{$\begin{array}{c}\text { Rule } \\
\text { No. }\end{array}$} & \multirow{2}{*}{ Workload } & \multirow{2}{*}{$\begin{array}{c}\text { Course } \\
\text { Repetition }\end{array}$} & \multirow{2}{*}{ Absences } & \multicolumn{2}{|c|}{ Course Grade } \\
\hline & & & & Output & Rounded Value \\
\hline 1 & 1 & 1 & 1 & 1.79 & 2 \\
\hline 2 & 1 & 1 & 2 & 0.39 & 1 \\
\hline 3 & 1 & 1 & 3 & 1.44 & 1 \\
\hline 4 & 1 & 2 & 1 & 1.61 & 2 \\
\hline 5 & 1 & 2 & 2 & 2.39 & 2 \\
\hline 6 & 1 & 2 & 3 & 0.34 & 1 \\
\hline 7 & 1 & 3 & 1 & 0.08 & 1 \\
\hline 8 & 1 & 3 & 2 & 0.12 & 1 \\
\hline 9 & 1 & 3 & 3 & 0.10 & 1 \\
\hline 10 & 2 & 1 & 1 & 2.42 & 2 \\
\hline 11 & 2 & 1 & 2 & 2.01 & 2 \\
\hline 12 & 2 & 1 & 3 & 1.23 & 1 \\
\hline 13 & 2 & 2 & 1 & 2.18 & 2 \\
\hline 14 & 2 & 2 & 2 & 0.59 & 1 \\
\hline 15 & 2 & 2 & 3 & 2.16 & 2 \\
\hline 16 & 2 & 3 & 1 & 0.11 & 1 \\
\hline 17 & 2 & 3 & 2 & 0.11 & 1 \\
\hline 18 & 2 & 3 & 3 & 1.59 & 2 \\
\hline 19 & 3 & 1 & 1 & 2.29 & 2 \\
\hline 20 & 3 & 1 & 2 & 0.74 & 1 \\
\hline 21 & 3 & 1 & 3 & 1.44 & 1 \\
\hline 22 & 3 & 2 & 1 & 2.05 & 2 \\
\hline 23 & 3 & 2 & 2 & 2.60 & 3 \\
\hline 24 & 3 & 2 & 3 & 3.24 & 3 \\
\hline 25 & 3 & 3 & 1 & 0.11 & 1 \\
\hline 26 & 3 & 3 & 2 & 0.23 & 1 \\
\hline 27 & 3 & 3 & 3 & 2.06 & 2 \\
\hline
\end{tabular}

\section{Discussion}

From the formulated rules, workload of ' 1 - Underload' have predominant prediction of a course grade of ' 1 - Fail'. This insight is counterintuitive on how workload affects academic performance. Ideally, less workload should improve student concentration and result to higher course grades. The counterintuitive finding may be a result of an underlying attribute unobservable with the current selection. Underloaded students may have enrolled in fewer units due to external duties and responsibilities. Meanwhile, RST's rule no. 2 is of particular concern as the rule predicts failure at a $100 \%$ accuracy. The rule is further supported by the 'in-between' generalization of ANFIS' rule no. 2. As pointed out by ANFIS' rules no. 1 to 3 , higher incurred absences with workload of ' 1 - Underload' and course repletion of ' 1 - None' yields higher chance of failure. Coupled with the failure rate among 
underloaded students, high rate of incurred absences may indicate that the student's focus is affected by external attributes.

RST's rules under workload of ' 2 - Normal Load', course grades are predominantly ' $2-$ Pass'. Students under this category may experience less demand from external attributes. In the case of ANFIS' rules for workload, some rules indicate a course grade of ' 1 - Fail'. The low output may be inferred to either hidden attribute interaction observed elsewhere or to nonexistent combinations. Inclusion of additional data will be needed. Meanwhile, RST's rules no. 5 to 7 show incurred absences has an inverse effect on course grade. The trend is similar with the earlier discussion on ANFIS' rules no. 1 to 3.

On rules for workload with ' 3 - Overload', course grade predictions are largely on '2 - Pass' and ' 3 - High'. The trend of workload indicates it is a positive attribute for course grade. Students taking higher workloads may possess confidence and willingness in performing exceptionally. Advisers can utilize such insight in determining student's commitment in accomplishing their enrolled units. Meanwhile, RST's rules no. 15 to 16 are among the notable ones in this workload category. The two rules depict attributes at its extremes, such that course repletion and incurred absences are at their highest. Even though the attributes are in the extremes, course grades are either ' $2-$ Pass' or ' 3 - High' at a 100\% accuracy. The two rules further highlight student's confidence in their enrolled course.

The two techniques attained satisfactory prediction performance. A portion of advisers may find the number of rules, however, difficult to utilize. Reduction of rules in future case studies may be considered to ease comprehension [49].

\section{Conclusion}

This study presented a framework on rule induction techniques for academic performance prediction using 'negative' attributes. The rule induction techniques, ANFIS and RST, were utilized. Overall, both models attained $70.83 \%$ accuracy rating and yielded 16 crisp rules and 27 fuzzy rules. Generated rules yielded insights on student characteristics and their course grade. Workload has shown an inverse effect on course grades possibly highlighting underlying effect of student's confidence. Incurred absences have a direct effect on course grades possibly indicating the attributes correlation with student's enthusiasm.

Limitations of the current work is lack of data and complexity of rule tables. The data considered academic performance of student's taking machine design courses. Inclusion of other courses, such as those requiring different skillsets, may yield dissimilar rule sets. Future works may consider other courses as the case study. The data is also bounded for only one term. As time progresses, additional data can be included. The addition will yield attribute combinations that is currently not evident. The rule tables are complex, such that 16 crisp rules and 27 fuzzy rules were generated. Reduction of the rules can provide simpler insight generalization and ease of use by academic advisers. 


\section{$7 \quad$ References}

[1] Yoder, B. (2016). Engineering by the numbers: ASEE retention and time-to-graduation benchmarks for undergraduate engineering schools. Washington, DC: American Society for Engineering Education.

[2] Miller, J. (1998). "Making connections through holistic learning", Educational Leadership, vol. 56 , no. 4 , pp. $46-48$.

[3] White, E. (2015). "Academic advising in higher education: a place at the core", The Journal of General Education, vol. 64 no. 4, 263-277. https://doi.org/10.5325/igeneeduc.64.4.0263

[4] Definitions of academic advising. Manhattan, KS: National Academic Advising Association, 2014.

[5] Williams, S. (2014). Applying theory to practice. Manhattan, KS: National Academic Advising Association.

[6] Creamer, D. G. (2000). "Use of theory in academic advising". San Francisco, CA: JosseyBass.

[7] Crookston, B. B. (1994). "A developmental view of academic advising as teaching”, NACADA Journal, vol. 14 no. 2, pp. 5-9.

[8] Han, Y. and Wei, H. (2016). "The academic advising models in american higher educational institutions", Higher Education Development and Evaluation, no. 6, p. 12.

[9] Harris, T. A. (2018). "Prescriptive vs. developmental: academic advising at a historically black university in South Carolina", The Journal of the National Academic Advising Association, vol. 38 no. 1, pp. 36-46. https://doi.org/10.12930/nacada-15-010

[10] Fielstein, L. L. (1989). "Student priorities for academic advising: Do they want a personal relationship?”, NACADA journal, vol. 9 no. 1, pp. 33-38. https://doi.org/10.12930/02719517-9.1.33

[11] Bolkan, S., Pedersen, W. C., Stormes, K. N. and Manke, B. (2018) "Predicting 4-year graduation: using social cognitive career theory to model the impact of prescriptive advising, unit load, and students' self-efficacy", Journal of College Student Retention: Research, Theory \& Practice, pp. 1-21. https://doi.org/10.1177/1521025118783485

[12] Earl, W. R. (1987). "Intrusive advising for freshmen", Academic advising news, vol. 9 no. 3.

[13] Vesper, M. and Dringenberg, E. (2016). “The implementation and preliminary impact of intrusive advising and an academic peer-mentoring program for engineering students" in ASEE Annual Conference.

[14] Murray W. S. and Le Blanc, L. A. (1995). "A decision support system for academic advising," in Proceedings of the 1995 ACM symposium on Applied computing - SAC '95. https://doi.org/10.1145/315891.315897

[15] Krumm, E., Waddington, R. J., Teasley, S. D. and Lonn, S. (2014). "A learning management system-based early warning system for academic advising in undergraduate engineering," in Learning Analytics, New York, NY: Springer New York, pp. 103-119. https://doi.org 10.1007/978-1-4614-3305-7 6

[16] Gue, I. H. V, Ubando, A. T., Tseng, M.-L. and Tan, R. R. (2020). “Artificial neural networks for sustainable development: a critical review," Clean Technol. Environ. Policy, vol. 22, no. 7, pp. 1449-1465. https://doi.org/10.1007/s10098-020-01883-2

[17] Abu-Naser, S. S., Zaqout, I. S., Abu Ghosh, M., Atallah, R. R. and Alajrami, E. (2015). "Predicting student performance using artificial neural network in the faculty of engineering and information technology", International Journal of Hybrid Information Technology, vol. 8 no. 2, pp. 221-228. https://doi.org/10.14257/ijhit.2015.8.2.20

[18] Sukhbaatar and Usagawa, T. (2019). "An Artificial Neural Network Based Early Prediction of Failure-Prone Students in Blended Learning Course", International Journal of Emerging 
Technologies in Learning, Vol. 14, No. 19, pp 77-92. https://doi.org/10.3991/ijet.v14i19 .10366

[19] Doshi-Velez F. and Kim, B. (2017). "Towards A Rigorous Science of Interpretable Machine Learning,” arXiv preprint, pp. 1-13.

[20] Mak B. and Munakata, T. (2002). "Rule extraction from expert heuristics: A comparative study of rough sets with neural networks and ID3," Eur. J. Oper. Res., vol. 136, no. 1, pp. 212-229. https://doi.org/10.1016/s0377-2217(01)00062-5

[21] Pekaslan, D., Chen, C., Wagner, C. and Garibaldi, J. M. (2020). "Performance and Interpretability in Fuzzy Logic Systems - Can We Have Both?" in Communications in Computer and Information Science. https://doi.org/10.1007/978-3-030-50146-4 42

[22] Bello R. and Falcon, R. (2017). "Rough Sets in Machine Learning: A Review," in Studies in Computational Intelligence. https://doi.org/10.1007/978-3-319-54966-8 5

[23] Hidayah, A. E. Permanasari, and N. Ratwastuti, (2013). "Student classification for academic performance prediction using neuro fuzzy in a conventional classroom" in International Conference on Information Technology and Electrical Engineering (ICITEE). https://doi.org/10.1109/iciteed.2013.6676242

[24] Mohsin, M. F. M., Hibadullah, C. F., Norwawi, N. M. and Wahab, M. H. A. (2010). "Mining the student programming performance using rough set" in IEEE International Conference on Intelligent Systems and Knowledge Engineering. https://doi.org/10.1109/iske.2010. $\underline{5680824}$

[25] Udristoiu, Udristoiu, S. and Popescu, E. (2014). "Predicting students' results using rough sets theory" in International Conference on Intelligent Data Engineering and Automated Learning. https://doi.org/10.1007/978-3-319-10840-7 41

[26] Zeidmane A. and Rubina, T. (2017). "Causes of Failures in Mathematics by Engineering Students at Latvia University of Agriculture,” Rural Environ. Educ. Personal., pp. 220-227.

[27] Amirkhan J. H. and Kofman, Y. B. (2018). "Stress overload as a red flag for freshman failure and attrition," Contemp. Educ. Psychol., vol. 54, pp. 297-308. https://doi.org/10.1016/ j.cedpsych.2018.07.004

[28] Kamal M. and Bener, A. (2009). "Factors contributing to school failure among school children in a very fast developing arabian society," Oman Med. J., vol. 24, no. 3, pp. 212-217.

[29] I. H. Gue, A. M. Sy, A. Nuñez, P. J. Loresco, J. G. and Onia, M. Belino, "Academic advising rules of engineering students on workload, course repetition, and absences," in Regional Conference on Engineering Education (RCEE), 2020 In press.

[30] Africa, A. D., Ching, G., Go, K., Evidente R. and Uy, J. (2019). "A comprehensive study on application development software systems." International Journal of Emerging Trends in Engineering Research. Vol. 7, No. 8, pp. 99-103.

[31] Teodoro, M. A., James Loresco, P. and Gorospe, M. A. C. (2019). "An Adaptive NeuroFuzzy Inference System Approach for Identifying Breakpoint Set for Directional Overcurrent Relays," in 2019 IEEE 11th International Conference on Humanoid, Nanotechnology, Information Technology, Communication and Control, Environment, and Management (HNICEM ), pp. 1-6. https://doi.org/10.1109/hnicem48295.2019.9073390

[32] Jang, J.-S. R. (1993). “ANFIS: adaptive-network-based fuzzy inference system," IEEE Trans. Syst. Man. Cybern., vol. 23, no. 3, pp. 665-685. https://doi.org/10.1109/21.256541

[33] Karaboga D. and Kaya, E. (2019). "Adaptive network based fuzzy inference system (ANFIS) training approaches: a comprehensive survey," Artif. Intell. Rev., vol. 52, no. 4, pp. 2263-2293. https://doi.org/10.1007/s10462-017-9610-2

[34] Pawlak, Z. (1999). "Rough sets," Int. J. Comput. Inf. Sci., vol. 11, no. 5, pp. 341-356, 1982.

[35] B. Walczak and D. L. Massart, "Rough sets theory," Chemom. Intell. Lab. Syst., vol. 47, no. 1, pp. 1-16. 
[36] Gerrard, D., Newfield, K., Balouchestani Asli, N. and Variawa, C. (2017). "Are students overworked? understanding the workload expectations and realities of first-year engineering," in ASEE Annual Conference \& Exposition Proceedings. https://doi.org/10.18260/1-2$\underline{-27612}$

[37] Sansgiry, S. S. and Sail, K. (2006). "Effect of students' perceptions of course load on test anxiety" American Journal of Pharmaceutical Education, vol. 70 no. 2, p. 26.

[38] Parkinson, T. J., Gilling, M. and Suddaby, G. T. (2006). "Workload, study methods, and motivation of students within a BVSc program," J. Vet. Med. Educ., vol. 33, no. 2, pp. 253265, doi: 10.3138/jvme.33.2.253. https://doi.org/10.3138/jvme.33.2.253

[39] Smith, A. P. (2019). "Student Workload, Wellbeing and Academic Attainment," in Communications in Computer and Information Science.

[40] Lieberman D. A. and Remedios, R. (2007). "Do undergraduates' motives for studying change as they progress through their degrees?” Br. J. Educ. Psychol., vol. 77, no. 2, pp. 379-395. https://doi.org/10.1348/000709906x157772

[41] Brox E. and Dörsam, M. "The Effects of Class Failure and Course Repetition on University Outcomes,” 2016. https://cemapre.iseg.ulisboa.pt/educonf/4e3/files/Papers/Brox.pdf

[42] Tafreschi, D. and Thiemann, P. (2016). "Doing it twice, getting it right? The effects of grade retention and course repetition in higher education" Economics of Education Review, vol. 55, pp. 198-219. https://doi.org/10.1016/j.econedurev.2016.10.003

[43] M. Armstrong and E. N. Biktimirov, "The Performance of New and Repeating Students in Introductory Economics,” J. Acad. Bus. Educ., vol. 15, pp. 84-96, 2014.

[44] Biktimirov, E. N. and Armstrong, M. J. (2015). "Is the second time the charm for students repeating introductory finance?”, Journal of Financial Education, pp. 32-49.

[45] Guleker, R. (2014). "The effect of attendance on academic performance" Mediterranean Journal of Social Sciences.

[46] Purcell, P. (2007). "Engineering student attendance at lectures: Effect on examination performance" in International Conference on Engineering Education, 2007.

[47] AbuRuz, M. E. (2015). "Does excessive absence from class lead to lower levels of academic achievement?” Eur. Sci. J., vol. 11, no. 7, pp. 146-153.

[48] Ahmad, N., Ul-Saufie, A. Z., Mohamed, S. A., Ahmat, H. and Zahari, M. F. (2018). "The impact of class absenteeism on student's academic performance using regression models," in AIP Conference Proceedings. https://doi.org/10.1063/1.5041712

[49] Africa, A. (2016). "A rough set-based data model for heart diseases diagnostics", ARPN Journal of Engineering and Applied Sciences, vol. 11, no. 15, pp. 9350-9357.

\section{Authors}

Ivan Henderson V. Gue is with De La Salle University, Manila, Philippines.

Alexis Mervin T. Sy is with FEU-Institute of Technology, Manila, Philippines.

Ailene B. Nuñez is with FEU-Institute of Technology, Manila, Philippines.

Pocholo James M. Loresco is with FEU-Institute of Technology, Manila, Philippines.

Jaychris Georgette Y. Onia is with FEU-Institute of Technology, Manila, Philippines.

Manuel C. Belino is with FEU-Institute of Technology, Manila, Philippines.

Jaychris Georgette Y. Onia is with Silliman University, Dumaguete, Philippines.

Article submitted 2021-05-26. Resubmitted 2021-07-01. Final acceptance 2021-07-05. Final version published as submitted by the authors. 